\title{
Design and Analysis of a Micro Tunnel Boring Machines (TBM)
}

\author{
Puran Singh \\ Department of Mechanical and Automation Engineering, Amity School of Engineering and Technology_Delhi, India \\ *Corresponding Author: puran.singh910@gmail.com
}

Copyright (C) 2014 Horizon Research Publishing All rights reserved.

\begin{abstract}
Tunnel boring machines (TBM) excavate tunnels with a circular cross section through a variety of rock strata. They can be used to bore through hard rock or sand and almost anything in between. Tunnel diameters can range from a metre (done with micro-TBMs) to 19 metres. Tunnel boring machines are used as an alternative to drilling and blasting (D\&B) methods. A TBM has the advantages of not disturbing surrounding soil and producing a smooth tunnel wall. This significantly reduces the cost of lining the tunnel, and makes them suitable to use in built-up areas. The key disadvantage is cost. TBMs are expensive to construct, difficult to transport and require significant infrastructure. A tunnel boring machine (TBM) typically consists of one or two shields (large metal cylinders) and trailing support mechanisms. At the front end of the shield a rotating cutting wheel is located. The cutting wheel will typically rotate at 1 to $10 \mathrm{rpm}$ (depending on size and stratum), cutting the rock face into chips or excavating soil (muck). A TBM can cut through rock at up to one kilometre a month. Powerful hydraulic rams force the machine's cutting head forwards as the rock is cut away called the feed. The action here is very much like an earthworm. The rear section of the TBM is braced against the tunnel walls and used to push the TBM head forward. At maximum extension the TBM head is then braced against the tunnel walls and the TBM rear is dragged forward. As tunnels has become one of the most important source of underground transportation like metro rail and other projects, this TBM can be utilized as an easy and effective machine for more better results. Because of their demonstrated capabilities in attaining high rates of advance in civil tunnel construction, the hard rock mining industry has always shown a major interest in the use of TBMs for mine developments. The successful application of TBM technology to mining depends on the selection of most suitable equipment and cutting tools for the rock and ground conditions to be encountered.
\end{abstract}

Keywords Rock Strata, Micro-Tbms, SPB

\section{Introduction}

A tunnel boring machine (TBM) is a machine used to excavate tunnels with a circular cross section through a variety of soil and rock strata. They can bore through hard rock, sand, and almost anything in between. Tunnel diameters can range from a metre (done with micro-TBMs) to 19 meters. Tunnels of less than a meter or so in diameter are typically done by horizontal directional drilling rather than TBMs.

Tunnel boring machines are used as an alternative to drilling and blasting (D\&B) methods in rock and conventional 'hand mining' in soil. A TBM has the advantages of limiting the disturbance to the surrounding ground and producing a smooth tunnel wall. This significantly reduces the cost of lining the tunnel, and makes them suitable to use in heavily urbanized areas. The major disadvantage is the upfront cost. TBMs are expensive to construct, difficult to transport and require significant infrastructure. The biggest is built by Herrenknecht AG of Schwanau, Germany to dig the $57 \mathrm{~km}$ Gotthard Base Tunnel. It has a diameter of 19 meters.

The first successful tunnelling shield was developed by Sir Marc Isambard Brunel to excavate the Thames Tunnel in 1825. Figure 1 indicates this tunnel. However, this was only the invention of the shield concept and did not involve the construction of a complete tunnel boring machine, the digging still having to be accomplished by the then standard excavation methods.

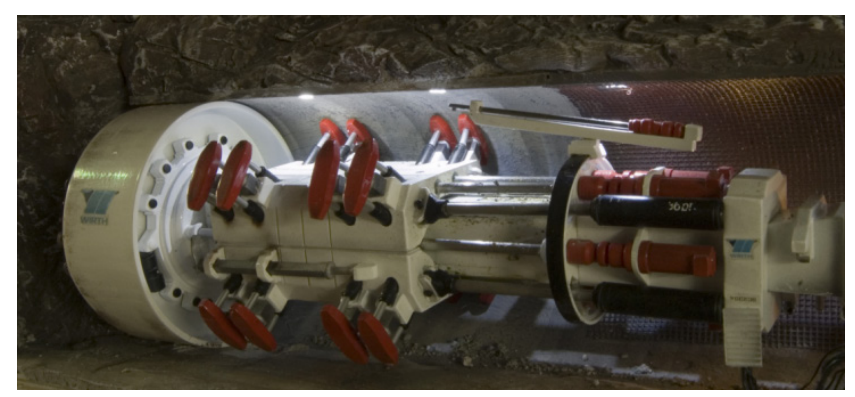

Figure 1. A tunnel boring machine TBM

The very first boring machine ever reported to have been built was Henri-Joseph Maus' Mountain Slicer. Commissioned by the King of Sardinia in 1845 to dig the 
Fréjus Rail Tunnel between France and Italy through the Alps, Maus had it built in 1846 in an arms factory near Turin. It basically consisted of more than 100 percussion drills mounted in the front of a locomotive-sized machine, mechanically power-driven from the entrance of the tunnel. Unfortunately, the Revolutions of 1848 irremediably affected the funding of the project and the tunnel was not completed until 10 years later, by using also innovative but rather less expensive methods such as pneumatic drills. ${ }^{[1]}$.

In the United States, the first boring machine to have been built was used in 1853 during the construction of the Hoosac Tunnel. Made of cast iron, it was known as Wilson's Patented Stone-Cutting Machine, after its inventor Charles Wilson. It drilled 10 feet into the rock before breaking down. The tunnel was eventually completed more than 20 years later, and as with the Fréjus Rail Tunnel, by using less ambitious methods.

In the early 1950 's, F.K. Mitry won a dam diversion contract for the Oahe Dam in Pierre, South Dakota, and consulted with James S. Robbins to dig through what was the most difficult shale to excavate at that time, the Pierre Shale. Robbins built a machine that was able to cut 160 feet in 24 hours in the shale, which was ten times faster than any other digging speed at that time.

The breakthrough that made tunnel boring machines efficient and reliable was the invention of the rotating head, conceptually based on the same principle as the percussion drill head of the Mountain Slicer of Henri-Joseph Mau, but improving its efficiency by reducing the number of grinding elements while making them to spin as a whole against the soil front. Initially, Robbins' tunnel boring machine used strong spikes rotating in a circular motion.

\section{Construction Methods Employed Using A TBM}

Tunnels are dug in various types of materials, from soft clay to hard rock, and the method of excavation depends on the ground conditions.

Cut-and-cover is a simple method of construction for shallow tunnels where a trench is excavated and roofed over. A strong overhead support system is required to carry the load of the covering material.

Two basic forms of cut-and-cover tunneling are available.

\subsection{Bottom-up Method}

A trench is excavated, with ground support as necessary, and the tunnel is constructed within. The tunnel may be of in situ concrete, precast concrete, precast arches, corrugated steel arches and such, with brickwork used in early days. The trench is then backfilled, with precautions regarding balancing compaction of the backfill material, and the surface is reinstated.

\subsection{Top-down Method}

In this method, side support walls and capping beams are constructed from ground level, using slurry walling, contiguous bored piles, or some other method. A shallow excavation is then made to allow the tunnel roof to be constructed using precast beams or in situ concrete. The surface is then reinstated except for access openings. This allows early reinstatement of roadways, services and other surface features. Excavation machinery is then lowered into the access openings, and the main excavation is carried out under the permanent tunnel roof, followed by constructing the base slab.

Shallow tunnels are often of the cut-and-cover type (if under water, of the immersed-tube type), while deep tunnels are excavated, often using a tunneling shield. For intermediate levels, both methods are possible.

Large cut-and-cover boxes are often used for underground metro stations, such as Canary Wharf tube station in London. This construction form generally has two levels, which allows economical arrangements for ticket hall, station platforms, passenger access and emergency egress, ventilation and smoke control, staff rooms, and equipment rooms. The interior of Canary Wharf station has been likened to an underground cathedral due to the sheer size of the excavation. This contrasts with most traditional stations on London Underground, where bored tunnels were used for stations and passenger access.

Tunnel boring machines (TBMs) and associated back-up systems can be used to highly automate the entire tunneling process. There are a variety of TBMs that can operate in a variety of conditions, from hard rock to soft water-bearing ground. Some types of TBMs, bentonite slurry and earth-pressure balance machines, have pressurised compartments at the front end, allowing them to be used in difficult conditions below the water table. This pressurizes the ground ahead of the TBM cutter head to balance the water pressure. The operators work in normal air pressure behind the pressurised compartment, but may occasionally have to enter that compartment to renew or repair the cutters. This requires special precautions, such as local ground treatment or halting the TBM at a position free from water. Despite these difficulties, TBMs are now preferred to the older method of tunneling in compressed air, with an air lock/decompression chamber some way back from the TBM, which required operators to work in high pressure and go through decompression procedures at the end of their shifts, much like divers.

Until recently the largest TBM built was used to bore the Green Heart Tunnel (Dutch: Tunnel Groene Hart) as part of the HSL-Zuid in the Netherlands. It had a diameter of 14.87 m. [1]

Nowadays even larger machines exist: two for the M30 ringroad in Madrid, Spain, and two for the Chong Ming tunnels in Shanghai, China. These machines are 15,2 $\mathrm{m}$ and $15,4 \mathrm{~m}$ in diameter respectively. The two machines for Spain were built by Mitsubishi/Duro Felguera and Herrenknecht. The TBMs for China were built by Herrenknecht.

The New Austrian Tunneling Method (NATM) was 
developed in the 1960s. The main idea of this method is to use the geological stress of the surrounding rock mass to stabilize the tunnel itself. Based on geotechnical measurements, an optimal cross section is computed. The excavation is immediately protected by thin shotcrete, just behind the excavation. This creates a natural load-bearing ring, which minimizes the rock's deformation.

By special monitoring the NATM method is very flexible, even at surprising changes of the geo mechanical rock consistency during the tunneling work. The measured rock properties lead to appropriate tools for tunnel strengthening. In the last decades also soft ground excavations up to $10 \mathrm{~km}$ became usual.

Pipe Jacking, also known as pipe jacking or pipe-jacking, is a method of tunnel construction where hydraulic jacks are used to push specially made pipes through the ground behind a tunnel boring machine or shield. This technique is commonly used to create tunnels under existing structures, such as roads or railways.

Other tunneling methods include:

Drilling and blasting

Slurry-shield machine

Wall-cover construction method.

\section{Choice of Tunnels vs. Bridges}

For water crossings, a tunnel is generally more costly to construct than a bridge. Navigational considerations may limit the use of high bridges or drawbridge spans intersecting with shipping channels, necessitating a tunnel. Bridges usually require a larger footprint on each shore than tunnels. In areas with expensive real estate, such as Manhattan and urban Hong Kong, this is a strong factor in tunnels' favor. Boston's Big Dig project replaced elevated roadways with a tunnel system to increase traffic capacity, hide traffic, reclaim land, redecorate, and reunite the city with the waterfront. Examples of water-crossing tunnels built instead of bridges include the Holland Tunnel and Lincoln Tunnel between New Jersey and Manhattan in New York City, and the Elizabeth River tunnels between Norfolk and Portsmouth, Virginia and the Westerschelde tunnel, Zeeland, Netherlands. Other reasons for choosing a tunnel instead of a bridge include avoiding difficulties with tides, weather and shipping during construction (as in the $51.5 \mathrm{~km}$ Channel Tunnel), aesthetic reasons (preserving the above-ground view, landscape, and scenery), and also for weight capacity reasons (it may be more feasible to build a tunnel than a sufficiently strong bridge).

Some water crossings are a mixture of bridges and tunnels, such as the Denmark to Sweden link and the Chesapeake Bay Bridge-Tunnel in the eastern United States.

There are particular hazards with tunnels, especially from vehicle fires when combustion gases can asphyxiate users, as happened at the Gotthard tunnel in Switzerland in 2001. One of the worst railway disasters ever occurred when a train stalled in the Armi tunnel in Italy in 1944, killing 426 passengers.

\subsection{TBM Design Considerations Geology}

The anticipated geological conditions along the alignment are critical to the selection of the machine.

The type of soil, rock and the presence of water have a fundamental impact on machine selection. The type of information typically provided include, soil/rock type and description, soil/rock strength parameters, grain size curves for soils, permeability (both primary and secondary) and the level of water above the tunnel alignment - or the lack of water as well. A simple change in the geology or the presence of water can change the type of machine from a simple open machine to a fully pressurized EPB or SPB type machine with complex operating parameters.

\subsubsection{Tunnel Alignment}

Other information critical to the selection of the TBM is the tunnel alignment. The TBM must be designed and built to be able to excavate the proposed tunnel along the pre-established line and grade. Items such as the minimum horizontal or vertical curve can have dramatic impact on the layout and configuration of the machine. A curve radius of $300 \mathrm{~m}$ is negotiable by most styles or types of machines but if the radius tightens to $200 \mathrm{~m}$ or less the design of the machine must be done carefully to ensure that the TBM and all of its ancillary equipment can negotiate the tighter curve.

Also, part of the alignment is the slope of the tunnel. Most metro or road and sewer tunnels have limited slopes based on their final use. However, there have been instances where slopes of $70 \%$ have been excavated. At this degree of incline (or decline) the TBM design has to consider the ergonomics of operation on a slope as well as the limitations of hydraulic systems. Also of interest to the manufacturers and designers of TBMs is the depth of the tunnel which can influence ground load pressures on the skin of the machine and the overall length of the tunnel drive and how it is broken up.

A machine designed to mine a tunnel $1500 \mathrm{~m}$ long is not the same as a machine designed to mine a tunnel $15,000 \mathrm{~m}$ long. The operation and principles of the machine may be the same but the selection of individual components will change in order to achieve the longer required operating life for the longer tunnel. The number of drives and their individual length will also influence machine design as frequent shafts will allow access to the cutting head for maintenance in a controlled environment where as widely spaced shafts (or none at all) may require additional measures (compressed air, mechanical face support doors etc.) to be available for accessing the cutting head in poor ground conditions.

\subsubsection{Site Restrictions}

Access to and the size of the job site will also impact the TBM selection. The size of the site, the ability to get cranes into the site to lift the TBM in and out of the shaft or portal will dictate the size of the individual pieces that the TBM can be shipped in. 
The location of the site can also restrict the allowable shipping size of individual components. The smaller the individual component that can be shipped to site the more time is required for disassembly at the manufacturing plant and reassembly on site. Items to consider when locating a site are: Available space: is it suitable for the installation of the equipment and for effective operation of the job site.

Restricted access: are the local roads leading to the site of sufficient size or capacity to allow the movement of large pieces of equipment and the removal of excavated material from the site in an efficient manner Available Equipment: is there a crane big enough locally to lift the maximum size of TBM component that will be sent. Shaft Dimensions: what are the dimensions of the shaft is there a head or tail tunnel, what room is available for assembly of the TBM for launch. All this will impact assembly and launch times on site. A TBM that can be set up in its full configuration at a portal can be assembled and launched to $100 \mathrm{~m}$ bored in two months. If we remove the ability to fully assemble and give minimum space to erect and launch the TBM the two months can become six months impacting project schedule and completion.

\section{Design and Fabrication of Micro Tunnel Boring Machine}

\subsection{Scope of Project}

There is a constant and growing demand in the mining industry for rapid excavation to develop new tunnels. The majority of civil engineering tunneling projects is now carried out by tunnel boring machines rather than drill and blast methods. Accurate estimation of production rates and costs of civil projects are vital points for using the TBM.

\subsection{Principle}

The main principle of TBM is the precise application of cutting tool and lead screw for providing constrained motion. Cutters are made of High Speed Steel and placed at an angle between $20 \mathrm{o}$ to $30 \mathrm{o}$ that besides cutting the rock also displaces the excavated soil directly behind the TBM.

Lead screw made of Mild Steel is used to provide forward thrust.

Two hollow cylinders are used. One for placing the motor and the second one holds the cutting head.

\subsection{Machine Parts: The Machine parts of TBM are as follows:}

Construction of tunnel boring machine TBM is as:

Two hollow cylinders

Cutting head

High Speed Steel Cutters

Ram to provide forward thrust

High torque DC motor to rotate cutting head

Microcontroller unit for controlling DC motor

Lead screw to connect motor and cylinder

Connecting rods to support the structure.

\subsection{Of Machine Parts}

4.4.1. Cutting Head

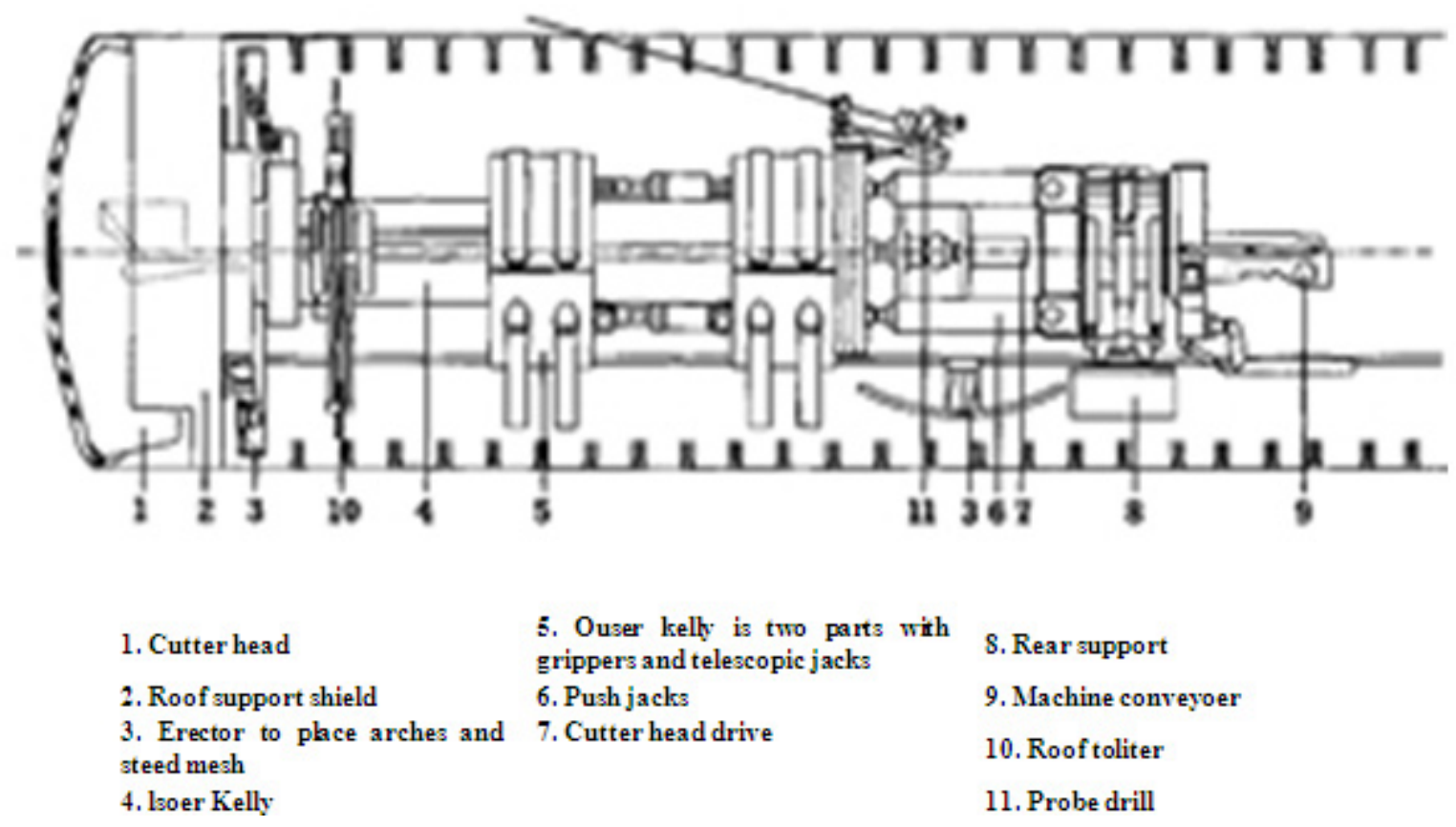

Figure 2. Construction of tunnel boring machine TBM 
Figure 2 shows the view of cutting head. It consists of round hollow M.S. ring of outer diameter of $350 \mathrm{~mm}$ and inner diameter of $300 \mathrm{~mm}$. Four strips are attached to the ring for mounting cutters.

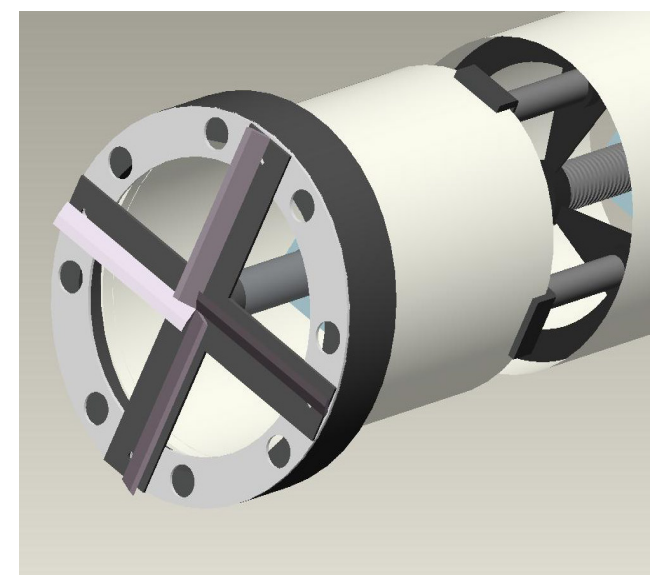

Figure 3. Cutting Head of TBM

\subsubsection{Cutter}

Four high speed steel cutters are used for cutting the material.

Cutters are attached to the ring.

They are inclined at an angle of around 25 degrees.

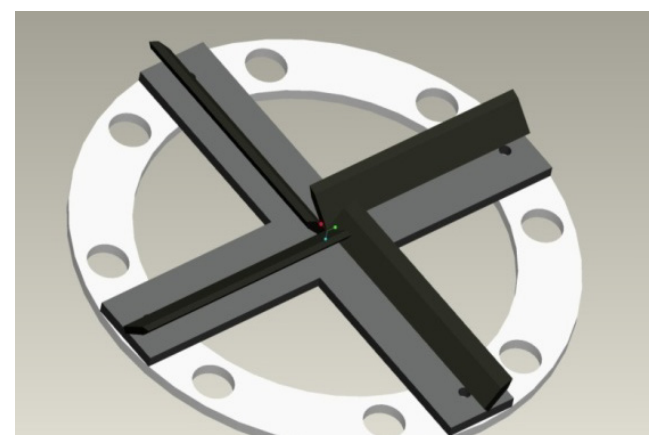

Figure 4. LEAD SCREW

A lead screw of $1 \mathrm{~mm}$ pitch is used to connect the D.C. motor with the $1^{\text {st }}$ cylinder. Lead screw provides the forward motion to the cylinders. Figure 3,4,5 lead screw connection.

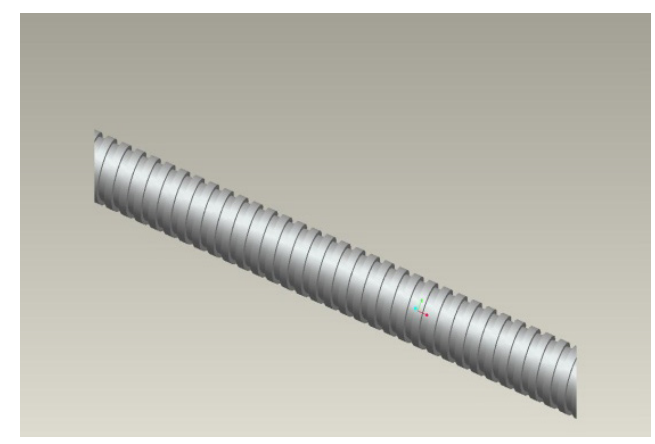

Figure 5. LEAD SCREW for TBM.

\subsubsection{D.C. Motors}

Two D.C. motors of high torque and low rpm are used in the
TBM.

One motor is used for the rotation and cutting operation of the cutting head.

Second motor is used to move the cylinder in forward direction.

\subsubsection{Cylinders}

Two strong steel cylinders are used in the TBM.

The first cylinder is connected directly with the cutting head through four M.S. strips.

The second cylinder contains the heavy DC motor.

The two cylinders are connected through a lead screw.

Figure 6 Assembled View For TBM.

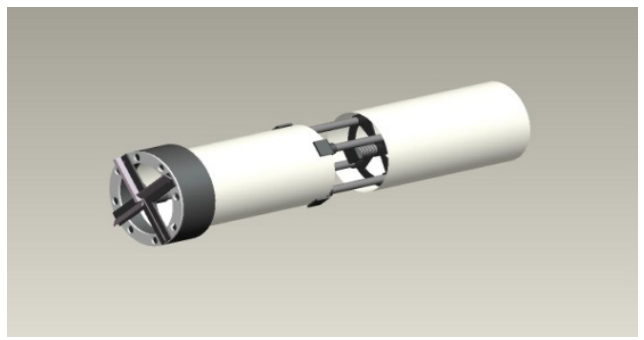

Figure 6. Assembled View For TBM.

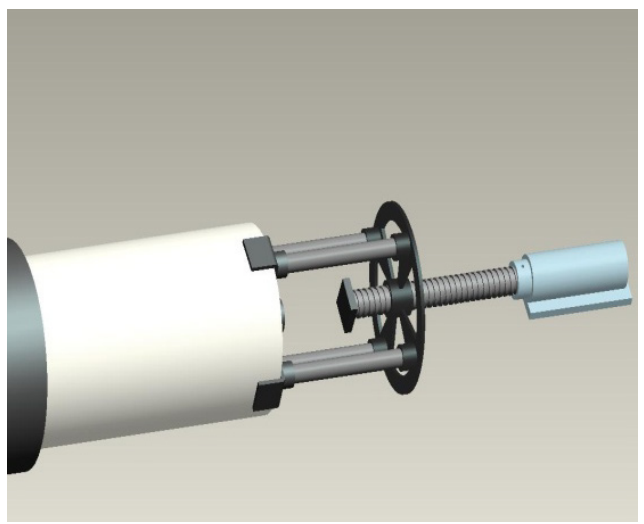

Figure 7. LEAD SCREW CONNECTION

\subsubsection{Microcontroller Unit}

It detects and controls the rotational speed of the motor. When speed is lower than the specified speed, it increases a control electric current. When speed is higher than the specified or required speed, it reduces a control electric current. It keeps a constant speed even if the load on the motor changes. It is used to control the starting and stopping of the lead screw coupled with the motor shaft and it also controls the speed of the cutting head.

\subsection{Parts of De Motor Controller}

\subsubsection{PIC16F873 Controller}

The control of the drive electric current of the motor is done by using the PWM function. The voltage according to the number of rotations of the motor is taken into the analog-to-digital converter and hence it controls the speed of the motor. Figure 7, PIC16F873 Controller. 


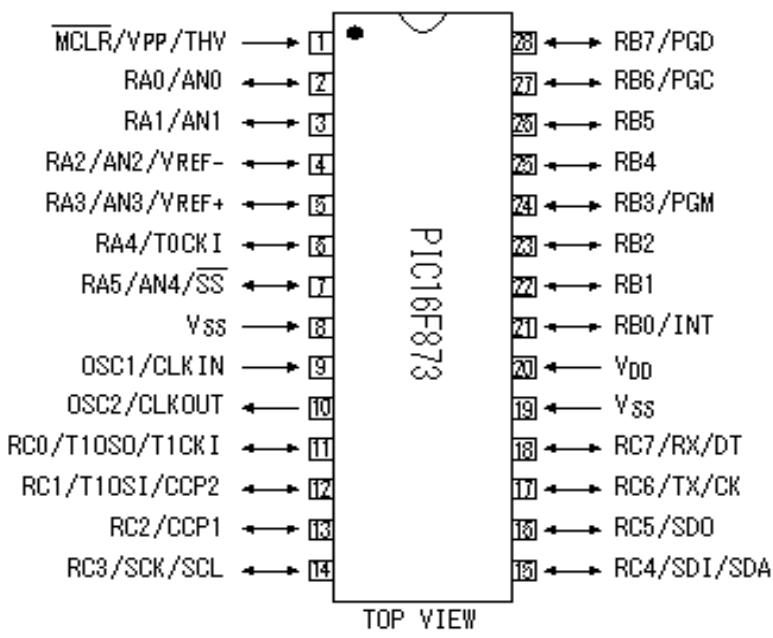

Figure 8. PIC16F873 Controller

\subsubsection{Advantages of Controlling A Dc-Motor With Above Mentioned MCU}

The motor has full torque at stand-still/ no-load condition (if the windings are energized).

Excellent response to starting/ stopping/ reversing.

It is more reliable since there are no contact brushes in the motor. Therefore the life of the motor is simply dependant on the life of the bearing.

It is possible to achieve very low speed synchronous rotation with a load that is directly coupled to the shaft.

A wide range of rotational speeds can be obtained, as the speed is proportional to the frequency of the input pulses.

\subsubsection{Factors Affecting Tbm Performance}

Bearing Strength of mud

Cutter geometry

Cutting tool material

Angle of inclination of the cutter

Operational parameters like friction between machine parts, fluctuation in input voltage, thermal stresses acting on the cutter due to friction.

\subsection{Design of Cutting Head}

Let inclination of the cutter w.r.t the axis of the cutting head be ' $\propto$ '

Let width of the cutter blade be ' $b$ ' $\mathrm{mm}$

Let the area of the face of the cutter be ' $A$ ',

So, pressure applied by the mud during rotation of the cutter will be subjected on the area ' $A$. $\sin (\alpha)$ ' and the load during linear translation will lie on ' $A \cdot \cos (\propto)$ '.

Let the bearing strength of mud be ' $\sigma$ ' $\mathrm{MPa}$

Let force acting on a small element ' $d A$ ' be ' $d F$ '

$\mathrm{dF}=\sigma \mathrm{dA}$

$\mathrm{dF}=\sigma \mathrm{b} \cdot \sin (\propto) \mathrm{dx}$

So, elemental torque acting due to force ' $\mathrm{dF}$ '

$d T=d F \cdot x$

$\mathrm{dT}=\sigma b \cdot \sin (\alpha) \cdot x d x$

Integrating both sides we get
$\mathrm{T}=\int(\sigma b \cdot \sin (\sigma) \cdot x) d x$

$\mathrm{T}=(1 / 2) b \cdot \sin (\propto)[r 22-r 12] \mathrm{Nm}$

For $\mathrm{n}$ blades,

$\therefore$ Total Torque $=n \times(1 / 2 \sigma b \cdot \sin (\alpha)[r 22-r 12] \mathrm{Nm}$

\subsection{Forces Acting During Linear Translation}

Area under subjected load $=A \cos (\alpha)$

$=b(r 2-r 1) \cos (\alpha)$

Bearing strength $=\sigma \mathrm{MPa}$

So, force acting on the blade will be

$F t=n b(r 2-r 1) \cos (\propto) X \sigma N$

Where,

$\mathrm{N}$ : no. of blades

\subsection{Design of Lead Screw}

Direct Tensile or Compressive Strength acting due to Axial Load

Direct Stress $=F t / A c$

Ac: Area corres. to core dia. of lead screw

Then, by Rankine Gordon Formula

$F t=A c X \sigma y[1-(\sigma y / 4 C \pi E)(L / k) 2]$

$\mathrm{C}$ : end fixity coeff.

E: mod of elasticity

\subsection{Design of Lead Screw in Shear}

The torque acting on the cutter during rotation will directly act on the lead screw

$\mathrm{T}=(\pi / 16)(d c) 3$

$\therefore d c=(16 T / \tau \pi) 1 / 3$

Shear due to axial load

cscrew $=W / \pi n 1 d c t$

$\mathrm{n}_{1}$ : no. of threads

Similarly for nut $\tau n u t=W / \pi n 1 d o t$

do: outer dia. of nut

\subsection{Power Required from Motor}

Torque Rating $=(1 / 2) b \cdot \sin (\alpha)[r 22-r 12] N m$

Let speed required be ' $N$ ' $r p m$

$\therefore \omega=2 \pi N / 60$

Power $=$ Torque $X \omega$

$\therefore$ Power $=(1 / 2) \sigma b \cdot \sin (\alpha)[r 22-r 12] X(\omega) K W$

CALCULATIONS

Bearing Strength of mud $=2 \mathrm{MPa}$

Diameter of Tunnel to be bored $=350 \mathrm{~mm}$

Area of X-sec of tunnel

$=3.14 *(350 / 2) 2 \mathrm{~mm} 2$

$=96211.3 \mathrm{~mm} 2$

Force required to bore tunnel $=A * \sigma$

$=192423 \mathrm{~N}$

$=192.423 \mathrm{kN}$

Taking Factor of Safety ' $f$ ' $=5$

Net force required $=5 \times 192.423$

$=962.423 \mathrm{kN}$ 
So, Torque acting on blades

$$
\begin{aligned}
& =(1 / 2) \times 2 \times \sin (25 o) \times(3502-102) \\
& =5172.47 \mathrm{Nm} \\
& \text { Torque per blade }=1293.211 \mathrm{~N}-\mathrm{m} \\
& \text { Area subjected under load }=A \cos (250) \\
& =96211 \times \cos (250) \\
& =87196.77 \mathrm{~mm} 2 \\
& \text { Force required in linear translation } \\
& =4 \times 25 \times(350-10) \cos (25 o) \times 2 \\
& =61629 \mathrm{~N} \\
& =61.63 \mathrm{kN} \\
& \text { Force per blade }=61.63 / 4 \mathrm{kN} \\
& =15.40 \mathrm{kN} \\
& \text { Direct Compressive Stress acting on the Lead Screw } \\
& =F t / \mathrm{Ac} \\
& =61629 /(3.14 x 12.52) \mathrm{MPa} \\
& =125.54 \mathrm{MPa}
\end{aligned}
$$

Material used (High Speed Steel) has a Tensile Strength of $320 \mathrm{MPa}$ (app.)

So, design is safe.

\subsection{Power Required from Motor}

Torque Requirement $=5172.9 \mathrm{~N}-\mathrm{m}$

Speed Requirement $=10 \mathrm{rpm}$ (as used in conventional TBM's )

so, angular speed ' $\omega$ ' $=2 * 3.14 * N / 60 \mathrm{rad} / \mathrm{s}$

$\omega=1.04 \mathrm{rad} / \mathrm{s}$

Power $=T \times \omega$

$=5172.9 \times 1.04$ Watts

$=5416.9 \mathrm{~W}=5.4 \mathrm{~kW}$

\subsection{Applications}

TBMs are used by DMRC for excavating tunnels.

Used in making of tunnel road.

Used in making of underground nuclear reactors.

Used in mining operations.

\subsection{Advantages}

It is accurate and precise.

A safe method in comparison to blast off methods.

Fast and efficient method.

Does not disturb surrounding rocks.

\section{REFERENCES}

[1] Hapgood Fred," The Underground cutting edge. The innovators who made digging tunnels hi-tech invention \& Technology”, VOL 20,\#2, Fall 2004
[2] Walters, D. "Sydney Airport Link Rail Tunnel Project, Des Walters: Under Pressure Underground". Descend Underwater Training Centre.. Retrieved on 2008-10-08.

[3] Bennett, MH; Lehm, J; Barr, P. "Medical support for the Sydney Airport Link Tunnel project.". Journal of the South Pacific Underwater Medicine Society32(2), http://archive.rubicon-foundation.org/7673. Retrieved on 8 October 2008.

[4] Hyatt N. Guidelines for Process Hazards Analysis, Hazards Identification and Risk Analysis, 3rd edition. 3 ed. Dyadem press, Ontario, Canada: 2003.

[5] Brauer RL. Safety and Health for engineers. 2nd edition. 2nd ed. Hoboken, New Jersey, USA: John Wiley 2002.

[6] SAEJ1739. Potential Failure Mode and Effects Analysis in Design (Design FMEA), in Manufacturing and Assembly Process (Process FMEA), and for Machinery (MFMEA). Society of Automotive Engineers, USA 1994. MIL-STD-1629A. Procedures for Performing a Failure Mode, Effects and Criticality Analysis. Department of Defense, USA 1998.

[7] Abdul-Nour G, Beaudoin H, Ouellet P, Rochette R, Ambert SL A. Reliability Based Maintenance Policy; A case study. Computers Ind Engng. 1998; 35 (3-4):591-4.

[8] Pinna T, Caporali R, Cambi G, Burgazzi L, Poucet A, Porfiri MT. Failure Mode and Effect Analysis on ITER heat transfer systems. Fusion Engineering and Design. 1998; 42:431-6.

[9] Sankar NR, Prabhu BS. Modified Approach for Prioritization of Failures in a System Failure Mode and Effects Analysis. Int J Qual Reliab Manage. 2001; 18 (3)(3):324-35.

[10] Scipioni A, Saccarola G, Centazzo A, Arena F. FMEA Methodology Design, Implementation and Integration with HACCP System in a Food Company. Food Control 2002; 13:495-501.

[11] Price CG, Taylor NS. Automated Multiple Failure FMEA. Reliability Engineering and System Safety 2002; 76:1-10.

[12] Seung JR, Ishii K. Using, Cost Based FMEA to Enhance Reliability and Serviceability Advanced Engineering Informatics 2003; 17:179-88.

[13] Seyed-Hosseini SM, Asgharpour MJ, Safaei N. Reprioritization of Failures in a System Failure Mode and Effect Analysis by Decision Making Trial and Evaluation Laboratory Technique. Reliability Engineering and System Safety 2006; 91:872-81.

[14] Dominguez - Garcia A, John K, Schindall J. Reliability Evaluation of the Power Supply of an Electrical Power net for Safety - Relevant Applications. Reliability Engineering and System Safety 2006; 91:505-14.

[15] Burgazzi L, Roberta F, Barbara G. Safety Assessment of a Lithium Target. Nuclear Engineering and Design 2006; 236:359-67.

[16] Eti MC, Ogaji SOT, Probert SD. Development and Implementation of Preventive Maintenance Practi 